\title{
School Engagement as Predictors of Academic Achievement of the Left-Behind Children in Henan Province, China
}

\author{
Wang Xiani ${ }^{1}$, Priyadarshini Muthukrishnan ${ }^{1}, \&$ Gurnam Kaur Sidhu ${ }^{1}$ \\ ${ }^{1}$ Faculty of Education, SEGi University, Kota Damansara, Selangor, Malaysia \\ Correspondence: Priyadarshini Muthukrishnan, Faculty of Education, SEGi University, Kota Damansara, \\ Selangor, Malaysia. E-mail: 1601625795@qq.com; priyakrishnan.mail@gmail.com
}

Received: April 13, 2019

doi:10.5539/ass.v15n7p16
Accepted: May 6, 2019

Online Published: June 30, 2019

URL: https://doi.org/10.5539/ass.v15n7p16

\begin{abstract}
With the expansion of industrialisation and rapid development of economy in China, migration of the rural population to the urban areas in seek of employment has resulted in changes in the family structure and increased number of left-behind children (LBC) in China. Numerous studies on LBC have concluded the critical issues among the children related to their overall well- being and their performance at school. The current study aimed to investigate the impact of emotional, cognitive and behavioural engagement of the LBC on the academic achievement of the left behind children. Quantitative research method was used and the sample were 186 leftbehind children in Henan Province, China. To measure school engagement, the instrument developed by Finlay (2006) was used. Correlation and hierarchical multiple regression analyses were conducted to examine the relationship between the various predictors and academic achievement. The findings concluded that emotional, cognitive and behavioural engagement of the LBC at school were significantly correlated with academic achievement. The hierarchical regression findings concluded that emotional engagement $(\beta=.268 ; \mathrm{t}=3.593$, $\mathrm{p}<0.000$, cognitive engagement $(\beta=.245 ; \mathrm{t}=3.284, \mathrm{p}<0.000$ and care takers $(\beta=.132 ; \mathrm{t}=2.009, \mathrm{p}<0.05)$ were significant predictors of academic achievement of the LBC.
\end{abstract}

Keywords: left-behind children, LBC in China, school engagement, emotional engagement, cognitive engagement, academic achievement

\section{Introduction}

Jia and Tian (2010) mentioned that in China, the migration of the rural population to urban areas in seek of employment has shown a tremendous increase over the last 35 years. Since the late 1970s, China's economy has driven industrialization, privatization and urbanization which have led to massive population of the country to migrate from rural to urban areas in seek of employment in the commercial industries. Many migrant workers are forced to leave their children in their rural community and in seek of lucrative occupations to improve their family condition and living. Studies have reported that most of the left-behind children's psychological state is more sensitive and fragile. To add, the children are at their growth stage and they undergo some sort of emotional and psychological ups and downs. The student's level of engagement is also affected by how a child's coping profile in respect of the pattern seen in stressful academic circumstances (Skinner, Kindermann, \& Purrer, 2009). School engagement is negatively related to drop out of school. Many studies suggested that the engagement in academics and out of class's activities by students are important in a student's academic success, and for some students, this is the factor that distinguishes between dropout and graduation (Audas \& Willms, 2001).

\subsection{The Emergence of Left-behind Children}

Since the late 1980s, the definition of LBC has been well explored. LBC refer to those children who are under the care of father and/or someone from an older generation and/or others and whose father and/or mother have been migrated to cities for work. Children below the young adult stage are categorized as LBC from this criterion. In other studies, the age of LBC is considered as 16 years and below (Hu \& Huang, 2017). The LBC are often under the guardianship of their grandparents and extended kin members. The migration and the LBC issues are rampant in most of the Asian countries. However, the magnitude of the phenomenon of migration and the population of the left behind children in China is alarmingly high. The rural-to-urban migration has not only affected the nation's economic boom, but to a large extent the lives of the people and significant portion of children in China. Pan (2002) had reported that 120-150 million migrant workers have moved to urban areas in the last two decades and had reached to 300 million by the end of the year in 2010. In rural areas, there is an 
increasingly large number of LBC, as residents in that area migrate to urban areas to seek employment due to imbalanced economy and rapid urbanization in China (All-China Women's Federation, 2013). According to recent national surveys, more than 58 million children in China were found to be left behind by their migratory parents, accounting for over $25 \%$ of the rural children. This number was almost three times higher than 20 million estimated in 2000 (All-China Women's Federation 2013).

According to the China's Sixth National Population Census Report (2010) 69.7 million LBC were reported among which 61 million of the LBC live in rural areas. Further, the report projected that $87.5 \%$ of the China's total number of LBC are in rural area and they contributed to $21.9 \%$ of the total number of children. All-China's Women Federation Survey (2013) reports estimated that 269 million rural residents have moved to cities by for employment opportunities. The magnitude of the migration of the adult population has been increasing and have significant impact on the social and political structure of the country. UNICEF (2014) has remarked as the largest human migration from rural-to-urban in the history. The individuals leave their rural homes and migrate to the cities in seek of better employment. Unfortunately, the migration of the adult population has affected the family structure of these individuals.

China's household registration system termed as "Hukou" that permits the citizens to access the public education system, health care and rights to buy houses in the urban area is restricted for the migrant workers. In 1950s, the Chinese government policy on residency and household registration allowed the citizens to register, preferably their birthplace as the residency and is approved by the local government (Liang \& Chen, 2007). The individual's local residency status registered at one place does not allow them to enjoy benefits at other places within China. Therefore, the migrant workers cannot opt for public services which are enjoyed by the urban residents. The study reported that migrant workers are marginalized and can hardly integrate into urban society due to their challenges faced in the urban economy, welfare system and cultural differences (Chen \& Wang, 2009). Kwong (2006) discussed that access to quality education is a critical factor in deciding the poor societal prospects. Due to the high cost of private services, the migrant workers are forced to leave behind their children in rural areas under the care of relatives. Duan (2005) identified that the emergences for LBC are due to the high cost of private education, child care services. Similar findings were reported by Wu and Ding (2004) that the social structure of Chinese society has the distinct rural-urban disparity and it is extremely difficult for the migrant workers to afford for their children's education and health care needs. This has resulted in the emergence LBC. China's government has initiated a series of policies, welfare and reforms to uplift the societal status of the LBC and the migrant population. Xu, Guan, and Yao (2011) have reported that Chinese government provides benefits, which include pension, basic health care services, occupational injury insurance through state owned organizations, NGOs and private corporations. However, the policy initiatives have not brought any fundamental changes in the residency and the household registration system. The Hukou system restricts rural children from enjoying the social benefits in urban regions. Although Chinese children are entitled to nine years of free public education, schooling at non-resident areas is legally prohibited. Wang and Holland (2011) and Lan (2014) reported that initial attention is sought for the children of rural migrants are given full rights to compulsory education (Wang \& Holland, 2011; Lan, 2014).

\subsection{School Engagement}

Engagement is a multifaceted construct that places significant emphasis on the different patterns in motivation, cognition and behaviour seen in students (Appleton, 2008; Sharma \& Bhaumik, 2013). Researchers have investigated this concept in detail for several decades, and the literature based on this topic consists of several different definitions, terms and coverage for the same notions of engagement (Baron \& Corbin, 2012; Fredricks et al., 2004; Upadyaya \& Salmela-Aro, 2013).

Engagement refers to the degree of participation, enthusiasm and value that a student puts into academic and non-academic activities in the school environment (Audas \& Willms 2002). Skinner, Wellborn, \& Connell (1990) define engagement as the student's initiation of effort, perseverance and action in regards to schoolwork and emotional states that they go through during the learning process. Kuh (2010) depicts student engagement as the energy and time placed into educational activities, within and outside the classroom, inclusive of the practices of educational organizations to inspire the student to take part in said activities. It is the commitment to learning, belonging and identifying as part of the school, by participating in events and activities to strengthen these concepts. Newmann (1992) coined the term "student engagement in academic work" to describe the psychological effort put in by the student towards the learning, understanding and mastering of skills and knowledge that their schoolwork promotes. A similar concept is also put forth by Wehlage, Rutter, Smith, Lesko, \& Fernandez (1989) who define educational engagement as the psychological investment required by the student to understand, and consequently master certain skills that are taught in educational institutions. 


\subsection{Dimensions of Engagement}

These varied definitions that appear in literature concerning the concept of engagement have their particular similarities and differences. Some similarities in definition include those put forth by Audas and Willms (2002), Skinner et al. (1990) and Willms (2003), which all are similar in terms of their emphasis placed on the participation and identification of the student with their educational setting and its related activities. Definitions proposed by Newmann (1992) and Wehlage et al. (1989) both relate engagement and the psychological investment that the student places in learning. Differences in definition include those of Kuh (2010). Kuh (2010) suggested that the concept of engagement is defined based on its relationship with the energy put into the learning process whereas Schaufeli et al. (2002) proposed that the motivational mindset that students have is correlated with vigour, dedication and absorption. Even with a broad range of definitions, the concept of engagement being a positive and active term to define the students' quality of participation, involvement, commitment and identification with the school-related activities and the school itself to affect their performance confidently remains constant.

The construct of engagement may be relatively broad with several different definitions, but researchers have come to the agreement that engagement is a multidimensional concept that includes several different aspects, such as behavioural, cognitive and emotional dimensions of Fredricks et al. (2004) model, and the vigour, dedication and absorption dimensions of Schaufeli et al.'s (2002) model. These dimensions operate together to provide the student with a positive perspective to their learning experiences (Carter et al., 2012; Schaufeli et al., 2002). The problem arises in identifying and defining the exact dimensions of engagement that exist, and to categorize several low-order factors into these dimensions (Li \& Lerner, 2011). An example is the difference in the number of dimensions in Schaufeli et al.'s (2002) model, which has three dimensions which is vigour, dedication and absorption as compared to the model proposed by Willms (2003) which only categorizes engagement into two dimensions (behavioural and psychological).

Engagement has been conceptualized as having two, three or four dimensions by different researchers. Jimerson Campos, \& Greif (2003) have proposed three-dimensional models that add to the former two-dimensional models with the new cognitive dimension of engagement. The model proposed by Jimerson, Campos, \& Greif (2003) has the effective dimension which is concerned with feelings towards the school, peers and teachers and the behavioural dimension that deals with the student's observable performance and action, and the cognitive dimension that can be described as the beliefs and perceptions that a student holds in regards to themselves, the school, teachers and peers.

The model by Appleton et al. (2006) consists of the behavioural dimension that is related to attendance, classroom participation, and extracurricular participation, whereas the psychological dimension that deals with the sense of belonging or identification with the school environment through relationships with teachers and peers, the cognitive dimension that deals with the value placed on learning, involvement in self-learning strategies, building personal goals and the degree of relevancy the student places on their school in regard to future endeavours and the academic dimension that is demonstrated by actions such as punctuality in submitting tasks, assignments and homework and the credit the student earns by the completion of their learning experience. Behavioural aspect includes involvement in learning activities through persistence, attention and effort, whereas the emotional dimensions talk about the student's degree of enthusiasm towards the subject matter. The cognitive dimension deals with the active utilization of self-regulation and skilled learning strategies and the agentic dimension that deals with the constructive contribution by the student towards the flow of instruction of the subject matter. The agentic dimension is fairly new, thus requiring much more research being done on it to properly validate this concept (Sinatra, Heddy, \& Lombardi, 2015).

\subsection{Problems of Left-behind Children}

Earlier research findings have concluded that parental migration has a significant influence in the children's developmental domains. Earlier studies have identified the psychological factors that impact students learning. Left-behind children in rural China experience higher levels of anxiety and poorer living conditions. The potential factors that influence learning are intellectual factors, non-intellectual factors and family environmental factors. It is generally believed that intelligence is a comprehensive cognitive ability, which includes five basic factors of attention, observation, memory, imagination and thinking. Also, the non-intellectual factors include motivation, interest, willing, temperament, personality and other basic factors. However, family environmental factors include family type, parental education, parental occupation, parental parenting.

The importance of cultural beliefs, values and the social structure contributes to the development of a better attitude towards learning and education. Every influencing factor represents a system. Each ethnic group has a 
fixed and self-evident value about academic learning. Clark (1983) thinks that a valid family has the following specific characteristics: has a sense of control of the children's life, so that often pass high expectations to the children and the family has a longing for the ideal of success in the future. Adding to those are having family-centered study per week and a family is seen as a mutually supportive system.

There have been many investigations carried out in developing countries like China, Ghana, Philippines and Mexico to study the effect of parental migration and negative impact on the psychological development of the children (Nobels, 2013; Zhao et al., 2014). In recent years, attention has been drawn towards the psychological problems associated with the LBC in facing their stressful life events. Various empirical research on the LBC have documented that these children suffer from lower nutrition (Tao et al., 2016, Tan et al., 2010), poor physical health (Shen et al., 2015), loneliness (Liu et al., 2010), depression and anxiety problems (He et al.; 2012; Zhao et al., 2014), poor academic performance Gao et al., 2010). Further, studies have reported high risk behaviors and suicidal attempts attempts among LBC (Gao et al., 2010), early dropouts from school (Gao et al., 2010), low self-esteem (Liu et al., 2010) and higher risk of disruptive behaviors which includes drinking alcohol, smoking and internet addiction (Jiang et al., 2013).

Costello, Erkanli, \& Angold (2006) have identified that at any given point of time the prevalence of clinical depression among children in the age group between 13 to 17 years is approximately $4-6 \%$. In the process of human development, the adolescence stage is termed as the stage of stress and strain and it is especially stressful due to the increased biological and psychological changes that occur during this stage (Arnett, 1999). There are remarkable changes in the brain and its function especially in the hippocampus and pre-frontal cortex region of the brain during adolescence. Adolescents are vulnerable to develop depression if they are exposed to stressful life situations in the adolescent stage (Andersen \& Teicher, 2008). Coyne's theory of psychological stress (1981), stated that stress includes stressors, mediator variables and physiological and psychological reactions. Major life events, sudden traumatic chronic tension is categorized as stressors while the mediator variables of stress include cognitive evaluation, social support, coping and sense of control. The stress is associated with psychological and physiological responses which involves changes of various emotional reactions, changes in physiological and biochemical indicators. The most common emotional reactions are depression and anxiety.

The living condition, family and school are potential factors to determine the school's engagement of the LBCs. Studies have shown that lack of parental involvement in caring and monitoring the children will affect the development of the children. For middle school children, schools have a direct influence on children's development. The school environment, teacher-student interaction, peer relationship is crucial for the children's emotional and social development. Studies have proved that children living conditions affect emotional and social behaviours. Many studies have been conducted on the impact of caretakers on the overall development and achievement of the LBCs. Studies have concluded that children who lived in the kinship foster system like grandparents and relatives displayed more emotional and behavioural problems (Zhao et al., 2014).

Protection and tracking of children are made available in the southwest of China's Guizhou Province for LBCs, by wearing smart wristbands with GPS that is directly linked to the local police database. This confirms that LBCs are at-risk and need constant monitoring and support system to ensure their well-being. Several studies have pointed out that the educational aspirations of the LBC are low and that has resulted in dropouts from school and the low percentage of the children completing their compulsory education (Koo, Ming, \& Tsang, 2014; UNICEF, 2014). Given that the importance of education is the key to lift one's own living to better standards, the life events that allow LBC to continue, complete and excel in their education despite these challenges is the need of the hour. The consequences of behavioural problems among children result in the serious disruption of their motivation in academics, self- inquiry and mental health problems (Montague, Enders, \& Castro, 2005; Marshall, Tilton-Weaver, \& Statin, 2013).

The purpose of the present study is to investigate the influence of school engagement on the academic achievement of the LBC. The independent variables considered in the study are school engagement while the dependent variable is academic achievement. The study attempted to identify the significant demographic variables and school engagement which relate the academic achievement of the LBC.

School engagement refers to the extent to which the left-behind children are engaged in the school in terms of effective, cognitive and behaviour engagement. School engagement includes the interaction of the students with the teachers and friends, their attitude towards their school and their attendance at school. This research focused dimensions are emotional engagement, cognitive engagement and behavioural engagement. Emotional engagement in the current study refers to interests, values and emotions of the children related to academics and their school. This includes affective reactions in the classroom, attitudes towards school and teachers, 
identification with school, feelings of belonging, appreciation of success in school (Finlay, 2006). The denotation of cognitive engagement refers to the motivation, effort and strategy use. This includes a mental and emotional investment in learning, a longing to reach further than just requisite and a liking for the challenge. This also involves the ability in problem-solving, the desire for hard work, interest in learning more than just behavioural engagement, psychological effort and determination to understand a task. Behaviour engagement dimension specifically refers to children engaging in school work and following the rules. It includes behaviours that show effort, persistence, concentration, attention, participating in classroom interaction and other school-related activities. Generally, emotional engagement is positive conduct of the children and the absence of disruptive behaviours at school (Finlay, 2006).

Though there are many studies conducted with the left-behind children, this research stands unique in terms of the variables selected for the study, the location of the research and the findings and the recommendations are at the end of this study.

\subsection{Research Questions}

This presents the finding of the following research questions.

1. What is the level of engagement of the LBC at school?

2. Is there any significant association between absenteeism of the LBC with respect to (i) their care takers, (ii) frequency of contact with their parents and (iii) frequency of meeting with their parents?

3. What are the significant predictors among the demographic variables and school engagement that predict academic achievement of the LBC?

\section{Method}

The study adopted quantitative research methods and used Survey questionnaires to collect data. SPSS 22.0v was used to analyse the data. The study considered left-behind students with the age range of 12 to 15 years old and studying in grade 8 of the middle school, located at San Men Xia in Henan province, China. Probability-sampling technique was used to select samples from 12 middle schools in San Menxia. From each school, five classes were selected randomly and about 16-17 left behind children from each school were considered for the study. After data cleaning procedures 186 data was finalised for further statistical analysis.

\subsection{Research Instruments}

The research instruments used consists of two parts. Part A of the questionnaire has the demographic variables of the participants and Part B to measure the left-behind children engagement at school, the present study adopted the questionnaire School engagement scale developed by Finlay, (2006). Based on the Quantifying school engagement: research report, Finlay, (2006) categorized the school engagement into three sub-scales: emotional engagement, cognitive engagement and behavioural engagement. The questionnaire consists of 30 items which are measured under three dimensions: emotional, cognitive and behavioural engagement. There are 13 items for emotional engagement, 12 items for cognitive engagement and 5 items for the behavioural engagement. The validity and reliability of the instruments were confirmed and the reliability scores greater than 0.80 were retained. The questionnaire has both positive and negative items. The participants responded to the questionnaire on five points Likert Scale that has the range of options from strongly disagree to strongly agree. The questionnaires were translated into Mandarin language by expert translators who are proficient in both English and Mandarin languages.

\section{Findings}

The following sections discuss the findings related to the research questions.

\subsection{Descriptive of the Demographic Variables}

Table 1. Distribution of Respondents by Demographic Variables

\begin{tabular}{llcc}
\hline & Demographic Variables & Frequency $(\mathrm{n}=186)$ & Percent $(\%)$ \\
\hline Gender & & Frequency & Percent (\%) \\
& Boy & 89 & 47.8 \\
& Girl & 97 & 52.2 \\
\hline Care Takers & & Frequency & Percent (\%) \\
& Grandparents & 52 & 14.9 \\
& Students' accommodation & 120 & 64.5 \\
& Relatives (Aunt/Uncle/Sibling) & 14 & 7.5 \\
\hline
\end{tabular}




\begin{tabular}{lcc}
\hline Parents' away from the children & 153 & 82.26 \\
Both parents are away & 23 & 12.36 \\
Only father & 10 & 6.53 \\
Only mother & & 20.4 \\
Frequency of contact with parents & 38 & 72.6 \\
Almost everyday & 135 & 5.4 \\
Almost every week & 10 & 1.6 \\
Almost every month & 3 & 78.0 \\
Once in six months & & 15.1 \\
Between 1- 3 months & 145 & 6.9 \\
Between 3-6 months & 28 & 13.4 \\
Once a year/more than a year & 13 & 74.2 \\
Frequency of meeting with parents & & 12.4 \\
Four to eight days a month & 25 & 100.0 \\
More than 8 days a month & 138 & 23 \\
Total & 186 & \\
\hline Frequency of absenteeism in school & & \\
\hline
\end{tabular}

\subsection{Descriptive of the School Engagement of the LBC}

The school engagement at school of the LBC is analysed and interpreted in the following section. The school engagement at school was analysed in three dimensions as emotional engagement, cognitive engagement and behavioural engagement. The analysis was carried out to find out the overall level of school engagement at school and the level of engagement with respect to each dimension. The following tables display the overall level of school engagement of the LBC and the level of engagement with respect to emotional, cognitive and behavioural dimensions.

Table 2. Descriptive of School Engagement of LBC

\begin{tabular}{cccccc}
\hline Engagement at school & Minimum & Maximum & Mean & SD & Level \\
\hline Emotional engagement & 2.33 & 4.33 & 3.51 & 0.34 & High \\
Cognitive engagement & 2.25 & 4.25 & 3.38 & 0.39 & High \\
Behavioural engagement & 1.60 & 4.40 & 2.44 & 0.52 & Low \\
Total engagement & 2.06 & 4.32 & 3.10 & 0.41 & Medium \\
\hline
\end{tabular}

(Scale: 1=Strongly Disagree; 2=Disagree; 3=Almost Agree; 4=Agree; 5=Strongly Agree)

Table 2 shows the overall descriptive analysis for the school engagement at school of the LBC. The mean score between 1.0 to 1.80 indicates a very low level, the mean score between 1.81 to 2.60 is considered as low level, the mean range between 2.61 to 3.20 indicates medium or average level, the mean range of 3.21 to 4.20 shows high level, and mean score from 4.21 to 5.00 specifies a very high level. The results indicated that the overall school engagement at school of the LBC is at medium level with mean score of $3.10(\mathrm{SD}=0.41)$. Further, the level of emotional engagement (Mean=3.51, $\mathrm{SD}=0.34$ ) and cognitive engagement is high (Mean=3.38, $\mathrm{SD}=0.39$ ) while the behavioural engagement is low (Mean $=2.44$ and $\mathrm{SD}=0.52$ ).

To find out whether there was any association among the care takers and absenteeism of the LBC, chi-square test of significance was conducted. The results are given in the table below.

Table 3. Association between Absenteeism and Care Takers of the LBC

\begin{tabular}{cccc}
\hline Absenteeism & \multicolumn{3}{c}{ Care takers } \\
\cline { 2 - 4 } & Grandparents & Students' accommodation & Relatives \\
\hline Three days a month & $9(7.5 \%)$ & $12(23.07 \%)$ & $9(28.57 \%)$ \\
Four to eight days a month & $100(83.3 \%)$ & $29(53.70 \%)$ & $1(7.1 \%)$ \\
More than 8 days a month & $11(9.16 \%)$ & $11(21.15 \%)$ & $14(100 \%)$ \\
Total & $120(100 \%)$ & $52(100 \%)$ & \\
\hline
\end{tabular}

A Chi-square test of independence was performed to examine the association between absenteeism of the LBC 
and care takers of the LBC. The test of association results indicated statistically significant difference in absenteeism of the LBC among the types of care takers, $\chi 2(4, n=186)=17.593, p<.05$. The students living with grandparents are more likely to be absent from school compared to the children living with in students accommodation or relatives. The results are represented in the Table 4 for the association between frequency of contact with the parents has any significant association with the absenteeism of the LBC. The test of association results indicated that absenteeism of the LBC does not appear to be statistically significant with the frequency of contact with parents. The results show that absenteeism is similar with respect to frequency of contact with parents, $\chi 2(4, \mathrm{n}=186)=6.974, \mathrm{p}>.05$.

Table 4. Association between Absenteeism of the LBC and Frequency of contact with Parents

\begin{tabular}{cccc}
\hline \multirow{2}{*}{ Absenteeism } & \multicolumn{3}{c}{ Frequency of contact with parents } \\
\cline { 2 - 4 } & Almost everyday & Almost every week & Almost every month \\
\hline Three days a month & $9(23.6 \%)$ & $13(9.6 \%)$ & $3(23.07 \%)$ \\
Four to eight days a month & $24(63.15 \%)$ & $105(7.77 \%)$ & $9(38.46 \%)$ \\
More than 8 days a month & $5(13.15 \%)$ & $17(12.5 \%)$ & $1(7.6 \%)$ \\
Total & $38(100 \%)$ & $135(100 \%)$ & $10(100 \%)$ \\
\hline
\end{tabular}

The findings for the association between absenteeism of the LBC and the frequency of meeting with their parents indicated that there was a significant association between the variables, $\chi 2(4, \mathrm{n}=186)=10.780, \mathrm{p}<.05$. The result is presented in Table 5. The students who meet their parents between 3 to 6 months were identified as the most frequent absentees to the school and they are absent to school between four to eight days in a month.

Table 5. Association between Absenteeism of the LBC and Frequency of meeting with Parents

\begin{tabular}{cccc}
\hline \multirow{2}{*}{ Absenteeism } & \multicolumn{3}{c}{ Frequency of meeting with parents } \\
\cline { 2 - 4 } & Between 1to3 months & Between 3 to 6 months & At least once a year \\
\hline Three days a month & $21(14.4 .0 \%)$ & $3(10.7 \%)$ & $1(7.6 \%)$ \\
Four to eight days a month & $107(73.8 \%)$ & $24(85.71 \%)$ & $7(53.8 \%)$ \\
More than 8 days a month & $17(11.7 \%)$ & $1(3.5 \%)$ & $5(38.46 \%)$ \\
Total & $145(78.0 \%)$ & $28(100 \%)$ & $13(100 \%)$ \\
\hline
\end{tabular}

The inter-relationship between the engagement and academic achievement is studied. The below Table 6 shows that the correlations between school engagement at school and academic achievement. The issue of multicollinearity among the variables of study was analysed and the inter-correlation matrix confirmed that all the correlation values are below 0.6 and therefore the data is suitable for the multiple correlational analysis.

Table 6. Relationship between School Engagement and Academic Achievement ( $\mathrm{n}=186)$

\begin{tabular}{ccccc}
\hline School engagement at school & Emotional engagement & $\begin{array}{c}\text { Cognitive } \\
\text { engagement }\end{array}$ & $\begin{array}{c}\text { Behavioural } \\
\text { engagement }\end{array}$ & $\begin{array}{c}\text { Academic } \\
\text { Achievement }\end{array}$ \\
\hline Emotional engagement & 1 & & & \\
Cognitive engagement & $.480^{* *}$ & 1 & & \\
Behavioural engagement & .000 & $.176^{*}$ & & \\
& .104 & .016 & 1 & \\
Academic Achievement & .157 & $.381^{* *}$ & $.028^{*}$ & 1 \\
\hline
\end{tabular}

$* * \mathrm{p}<0.01, * \mathrm{p}<0.05$

According to the correlation matrix, the correlation between cognitive engagement and emotional engagement $(\mathrm{r}=0.480, \mathrm{p}<0.01)$ is significantly positive. Behavioural engagement showed significant and negative correlations with emotional engagement and cognitive engagement. Academic achievement illustrated significant and positive correlations with emotional engagement $(r=0.397, p<0.01)$, cognitive engagement $(r=0.381, p<0.01)$ and behavioural engagement $(\mathrm{r}=0.028, \mathrm{p}>0.05)$.

Table 7 and 8 show the results of hierarchical regression for demographic variables and school engagement as a predictor on academic achievement of the LBC.

In the first step of the regression model, the demographic variables which include gender, caretakers, age of the $\mathrm{LBC}$, parents staying away from the children, frequency of meeting the parents and frequency of contact with the 
parents were entered as the predictors of academic achievement of LBC. The model confirmed that only care takers as the significant predictor among the demographic variables and other variable were not significant. This model accounted for only $2.8 \%$ of the variance in academic achievement. In the next step, the three dimensions of school engagement were added. Model 2 was significant which consisted of caretakers and emotional engagement of the LBC, and these predictors accounted for $17.6 \%$ of the variance of the criterion variable. This was followed by the final model which considered cognitive engagement along with the other two predictors of model 2. All the three models were significant and the final model could explain $22.2 \%$ of the variance of the in academic achievement. The final model confirmed that emotional engagement $(\beta=.268 ; \mathrm{t}=3.593, \mathrm{p}<0.000)$ is the most significant predictor of all the variables involved in the model. The second predictor identified was cognitive engagement $(\beta=.245 ; \mathrm{t}=3.284, \mathrm{p}<0.000)$, followed by caretakers $(\beta=.132 ; \mathrm{t}=2.009, \mathrm{p}<0.05)$.

Table 7. Regression of care taker and School Engagement on Academic Achievement: Model Summary

\begin{tabular}{|c|c|c|c|c|c|c|c|c|}
\hline \multirow{2}{*}{ Model } & \multirow{2}{*}{$\mathrm{R}$} & \multirow{2}{*}{ R Square } & \multirow{2}{*}{ Adjusted R Square } & \multirow{2}{*}{ Std. Error of the Estimate } & \multicolumn{4}{|c|}{ Change Statistics } \\
\hline & & & & & R Square Change & F Change & df1 df2 & Sig. F Change \\
\hline 1 & $.167^{\mathrm{a}}$ & .028 & .023 & 10.15673 & .028 & 5.265 & 1184 & .023 \\
\hline 2 & $.419^{\mathrm{b}}$ & .176 & .167 & 9.37825 & .148 & 32.815 & 1183 & .000 \\
\hline 3 & $.471^{\mathrm{c}}$ & .222 & .209 & 9.13709 & .046 & 10.787 & 1182 & .001 \\
\hline
\end{tabular}

a. Predictors: (Constant), Care taker

b. Predictors: (Constant), Care taker, Emotional Engagement

c. Predictors: (Constant), Care taker, Emotional Engagement, Cognitive Engagement

d. Dependent Variable: academic achievement

Table 8. Standardised Coefficients for School Engagement at School as Predictor for Academic Achievement

\begin{tabular}{|c|c|c|c|c|c|c|}
\hline & \multirow{2}{*}{ Model } & \multicolumn{2}{|c|}{ Unstandardized Coefficients } & \multirow{2}{*}{$\frac{\text { Standardized Coefficients }}{\text { Beta }}$} & \multirow{2}{*}{$\mathrm{t}$} & \multirow{2}{*}{ Sig. } \\
\hline & & $\mathrm{B}$ & Std. Error & & & \\
\hline \multirow{2}{*}{1} & (Constant) & 43.274 & 3.795 & & 11.404 & .000 \\
\hline & Care taker & 3.054 & 1.331 & .167 & 2.295 & .023 \\
\hline \multirow{3}{*}{2} & (Constant) & 3.812 & 7.729 & & .493 & .622 \\
\hline & Care taker & 2.484 & 1.233 & .136 & 2.015 & .045 \\
\hline & Emotional Engagement & 11.697 & 2.042 & .386 & 5.728 & .000 \\
\hline \multirow{4}{*}{3} & (Constant) & 5.179 & 8.012 & & .646 & .519 \\
\hline & Care taker & 2.413 & 1.201 & .132 & 2.009 & .046 \\
\hline & Emotional Engagement & 8.139 & 2.265 & .268 & 3.593 & .000 \\
\hline & Cognitive Engagement & 6.415 & 1.953 & .245 & 3.284 & .001 \\
\hline
\end{tabular}

a. Dependent Variable: academic achievement

\section{Discussion}

The descriptive analysis of left-behind children's engagement at school using a five-point scale showed an average level of overall school engagement $(\mathrm{M}=3.10, \mathrm{SD}=0.41)$. Further, dimension wise results reported that, the level of emotional engagement $(\mathrm{Mean}=3.51, \mathrm{SD}=0.34)$ and cognitive engagement were average (Mean=3.38, $\mathrm{SD}=0.39$ ) while the behavioural engagement was low (Mean $=2.44$ and $\mathrm{SD}=0.52$ ). The hierarchical regression findings concluded that emotional engagement, cognitive engagement and caretakers were significant predictors of academic achievement of the LBC.

The current study findings agreed with various studies related to educational outcomes of LBC and parents' migration. Earlier studies on parental migration on children's well-being and educational outcomes have concluded that parental absence caused by international migration had negatively affected both the educational outcomes and psychological well-being of the children (Giannelli \& Mangiavacchi, 2010; Senaratna, 2012). Ye \& Pan (2011) study analysed the daily routines, emotional well- being and general life factors and found that LBCs displayed negative affect towards increased academic workloads due to lack of tutoring and supervision. Furthermore, the children who were under the care of grandparents were the poor academic performers. Similar findings were concluded by $\mathrm{Lu}$ (2012) regarding parental migration and educational prospects of the LBCs. The study confirmed that younger children are more susceptible to the disruptive effect of parent's migration. In the absence of parental support, the LBC often lack the support they need in education and ultimately do not succeed at school. The statistical evidence that support the prevalence of behavioural problems have been widely researched. Earlier studies have reported that the prevalence of behavioural problems in China was about $12.9 \%$ 
among the children age group 4 to 16 years (Xin \& Zhang, 1992). Findings from Jia \& Tian (2010) concluded that LBC are prone to develop depression compared to their counterparts, NLBC. They reported that $2.5 \%$ of LBC are more likely to suffer from loneliness and tend to develop depression. Earlier studies have concluded that LBC have severe psychological problems compared to NLBC. Furthermore, the causes for the behavioural problems are analysed by Luo et al., (2016) and they identified that LBC has more feelings of abandonment and neglect. Consequently, this attitude resulted in developing less pro-social behaviours among LBC. Gao (2013) argued that $\mathrm{LBC}$ are prone to suffer from physical and psychological damages due to parental migration. Cases such as severe injuries, juvenile delinquency, increased rates of sexual activities, drug uses, and illicit activities among youth, and sometimes even death, take place without proper parental supervision and guidance in life. For better school engagement of the LBC, the teacher-student interaction, the guidance and support available at school plays vital factors to improve school engagement. The current study showed that LBC are able to share their problems with teachers, teachers heed to their problems and treat them fairly at school. This showed better support available for the LBC at school. The related literature on the behavioural engagement of LBC has been extensively studied and the studies highlighted the behavioural problems faced by LBC at home and school. The findings of $\mathrm{Hu}, \mathrm{Lu} \&$ Huang (2014) on the comparative study of migrant and left-behind children reported that the left-behind children exhibited many behavioural issues compared to migrant children.

The present study findings concluded that LBC living with grandparents are more likely to be absent from school compared to the children living in the students' accommodation or their relatives. Su et al. (2012) supported the current findings, that LBC who were left-behind at their early childhood years, had no elder siblings, were under the care of non-relatives displayed more complex psychological problems Earlier studies also concluded that LBC with better family function and social support had lesser psychological problems ( $\mathrm{Su}$ et al., 2012) highlighted that studies related to impact of coping styles, self- esteem and personality on the mental health of the LBC are yet to be studied. The findings of the study coincide with the findings from Lv (2006) which established that children with migrant parents have increased labour burdens, affecting the amount of time and effort that they could spend on their schoolwork and studies at home. Moreover, they lack a family tutor to help them in any areas of misunderstanding or doubt in their academics (Ye \& Murray, 2005; Cao, 2007). On similar lines, Wang (2013) highlighted that LBC under the care of grandparents or relatives are found to assume the role of caregivers in household chores. LBC is involved in providing care for their younger siblings or elderly people. These striking findings concluded that the LBC children staying with parents are involved in additional roles and they are deprived of care, work- free and idyllic phase of childhood life. Therefore, these LBC do not receive adequate adult supervision and care under their caretakers. Their study concluded that LBC are independent and capable of taking care of themselves without adult supervision. Therefore, the study brought new insights to the existing literature on LBC that the importance of emotional and cognitive engagement of the LBC at school. Further, it concludes that LBC staying with grandparents were frequent absentees' school, which affects their academic performance.

\section{Conclusion}

The current study presented the cross-sectional and empirical evidence for the school engagement and academic achievement of the LBC. The findings of the study concluded that the school engagement of the LBC is moderate, however, the school engagement with respect to behaviour engagement is low. The inferential statistics have identified emotional and cognitive engagement were reported significance towards the academic achievement of the LBC. Despite, the limitations, the study has brought valuable insights to the existing literature. The study recommended the effective measures to provide family and social support system for the LBC. In the future, effective protective measures and support system should be implemented to address the unique needs of the LBC. The study recommends innovative approaches in creating collaborative and joint responsibilities and initiatives in providing better school engagement of the LBC through childparents-care-takers- school support system that aims to empower the lives of the LBC.

\section{References}

All-China Women's Federation. (2013). Investigation report on condition of left-behind children and migrant children in rural China. Retrieved from http://acwf.people.com.cn/n/2013/0510/c99013-21437965.html

Appleton, J. J., Christenson, S. L., Kim, D., \& Reschly, A. L. (2006). Measuring cognitive and psychological engagement: Validation of the student Engagement Instrument. Journal of School Psychology, 44(5), 427-445. http://dx.doi.org/10.1016/j.jsp.2006.04.002

Appleton, J. J., Christenson, S. L., \& Furlong, M. J. (2008). Student engagement with school: Critical conceptual and methodological issues of the construct. Psychology in the Schools, 45(5), 369-386. 
http://dx.doi.org/10.1002/pits.20303

Andersen S. L., \& Teicher, M. H. (2008). Stress, sensitive periods and maturational events in adolescent depression. Trends in Neuro science, 31, 183-19. https://doi.org/10.1016/j.ynstr.2018.100140

Arnett, J. J. (1999). Adolescent storm and stress, reconsidered. American Psychologist, 54(5), 317-326. http://dx.doi.org/10.1037/0003-066X.54.5.317

Audas, R., \& Willms, J. D. (2001). Engagement and Dropping Out of School: A Life-Course Perspective. Applied Research Branch, Human Resources Development Canada. Retrieved from http://sbisrvntweb.uqac.ca/archivage/15292281.pdf

Audas, R., \& Willms, J. D. (2002). Engagement and dropping out of school: A life-course perspective. Retrieved from http://sbisrvntweb.uqac.ca/archivage/15292281.pdf

Baron, P., \& Corbin, L. (2012). Student engagement: Rhetoric and reality. Higher Education Research \& Development, 31(6), 759-772. https://doi.org/10.1080/07294360.2012.655711

Cao, C. (2007). Analyzing study performance of rural left-behind children. Education Exploration and Practice, 5, 73-74 (original in Chinese).

Carter, C. P., Reschly, A. L., Lovelace, M. D., Appleton, J. J., \& Thompson, D. (2012). Measuring student engagement among elementary students: Pilot of the Student Engagement Instrument-Elementary Version. School Psychology Quarterly, 27(2), 61-73. https://psycnet.apa.org/doi/10.1037/a0029229

National Bureau of Statistics of China. (2012). Retrieved from http://www.stats.gov.cn/english/Statisticaldata/AnnualData/

Chen, X. W. (2009). Shyness-sensitivity and social, school, and psychological adjustment in rural migrant and urban children in China. Child Development, 80(5), 1499-1513.

Clark, R. M. (1983). Why Poor Black Children Succeed or Fail. Eligible submission s to Youiig Scholar's program. Retrieved from https://storage.rockarch.org/01cf0cdf-d132-4844-ac21-417b720174be-FCD001_ 102_00254.pdf

Costello, E. J., Erkanli, A., \& Angold, A. (2006). Is there an epidemic of child or adolescent depression? J Child Psychol Psychiatry, 47(12), 1263-71. https://doi.org/10.1111/j.1469-7610.2006.01682.x

Duan, C. Z. (2005). Research on the left-behind children in China. Population Research, 29, 29-36. (in Chinese).

Finlay, K., \& National Center for School Engagement. (2006). Quantifying school engagement: Research report. Retrieved from http://www.schoolengagement.org/TruancypreventionRegistry/Admin/Resources/Resource s/111.pdf

Fredricks, J. A., Blumenfeld, P. C., \& Paris, A. H. (2004). School Engagement: Potential of the Concept, State of the Evidence. Review of Educational Research, 2004. https://doi.org/10.3102\%2F00346543074001059

Gao, H. (2013). Chine's Left Behind. World Policy Journal, 30(2), 29-38. https://doi.org/10.1177/0740277513494060

Gao, Y., Li, P. L., Kim, J., Congdon, N., Lau, J., \& Griffiths, S. (2010). The impact of parental migration on health status and health behavior among left behind adolescent school children in China. BMC Public Health, 10(1). https://doi.org/10.1186/1471-2458-10-56.

Giannelli, G. C., \& Mangiavacchi, L. (2010). Children's Schooling Parental Migration: Empirical Evidence on the Left-Behind Generation in Albania. https://doi.org/10.1111/j.1467-9914.2010.00504.x

He, B., Fan. J., Liu, N., Li, H., Wang Y., Williams, J., \& Wong, K. (2012). Depression risk of left-behind children in rural China. Psychiatry Res, 306-312. https://doi.org/10.1016/j.psychres.2012.04.001

Hongwei, H. et al. (2018). A Comparative Study of Behavior Problems among Left-Behind Children, Migrant Children and Local Children. Int. J. Environ. Res. Public Health, 15, 655.

Hu, H. W., Lu, S., \& Huang, C. C. (2014). The psychological and behavioral outcomes of migrant and left-behind children in China. Children and Youth Services Review, 46, 1-10.

Jia, Z., \& Tian, W. (2010 ). Loneliness of left-behind children: A cross-sectional survey in a sample of rural China. Child Health and Development, 36(6), 812-817. https://doi.org/10.1111/j.1365-2214.2010.01110.x

Jiang, Y., Sun, Y., Yang, L., Chen, M., Lv, L., Sun, Y., \& Zhang, H. Y. S. (2013). Analysis on the resilience of 
left-behind children in rural Anhui Province and its associated factors. China Journal of School Health, (3), 365-367.

Jimerson, S. R., Campos, E., \& Greif, J. L. (2003). Toward an Understanding of Definitions and Measures of School Engagement and Related Terms. California School Psychologist, 8, 7-27. http://dx.doi.org/10.1007/BF03340893

Koo, A. H., Ming, H., \& Tsang, B. (2014). The doubly disadvantaged: How return migrant students fail to access and deploy capitals for academic success in rural schools. Sociology, 48, $795-811$. https://doi.org/10.1177/0038038513512729

Kwong, J. (2006). The Integration of migrant children in Beijing schools. In G. A. Postiglione (Ed.), Education and social change in China: Inequality in a market economy (pp. 163-178). Armonk, NY: M.E. Sharpe.

Kuh, G. D. (2010). What We're Learning About Student Engagement From NSSE: Benchmarks for Effective Educational Practices. Change: The Magazine of Higher Learning, 35(2), 24-32. http://dx.doi.org/10.1080/00091380309604090

Lan, P. C. (2014). Segmented incorporation: The second generation of rural migrants in Shanghai. The China Quarterly, 217, 243-265. Retrieved from http://journals.cambridge.org/abstract_S030574101300146X

Li, Y., \& Lerner, R. M. (2011). Trajectories of school engagement during adolescence: implications for grades, depression, delinquency, and substance use. Deve. Psy., 47(1), 233. https://doi.org/10.1037/a0021307

Liang, Z., \& Chen, Y. P. (2007). The educational consequences of migration for children in China. Social Science Research, 36(1), 28-47. http://dx.doi.org/10.1016/j.ssresearch.2005.09.003

Liu, L. J., Sun, X., Zhang, C. L., Wang, Y., \& Guo, Q. (2010). A survey in rural China of parent-absence through migrant working: the impact on their children's self-concept and loneliness. BMC public health, $10(1), 32$. https://doi.org/10.1186/1471-2458-10-32

Lu, Y. (2012). Education of children left behind in rural China. Journal of Marriage and Family, 74(2), $328-341$. https://dx.doi.org/10.1111\%2Fj.1741-3737.2011.00951.x

Luo, et al. (2016). Resilience in rural left-behind middle school students in Yunyang County of the Three Gorges area in China: A prospective cohort study. BMC Psychiatry, 16(77). https://dx.doi.org/10.1186\%2Fs12888016-0781-1

Lv, S. (2006). Research on the issue of left-behind children in rural China. Chinese Women's Movement, 6,19-25.

Marshall, S., K., LC, T. W., \& Stattin, H. (2013). Non-suicidal self-injury and depressive symptoms during middle adolescence: A longitudinal analysis. J. Youth Adolesc., 42, 1234-1242. https://dx.doi.org/10.1007/s10964-013-9919-3

Montague, M. E. (2005). Academic and Behavioral Outcomes for Students at Risk for Emotional and Behavioral Disorders. Behav. Disord., 31, 84-94. Retrieved from https://asu.pure.elsevier.com/en/publications/ academic-and-behavioral-outcomes-for-students-at-risk-for-emotion

Newmann, F. M. (1992). The significance and sources of student engagement. In F. M. Newmann (Ed.), Student engagement and achievement in American secondary schools (pp. 11-39). Teachers College Press.

Nobles, J. (2013). Nobles Migration and father absence: Shifting family structure in Mexico. Demography, 50(4), 1303-1314. https://dx.doi.org/10.1007\%2Fs13524-012-0187-8

Pan, P. (2002). Poisoned Back to Poverty: As china Embraces Capitalism, Hazards to Worker Rise. Washington.

Sixth National Population Census Office of State Countil. (2010). Major figures on population census of China [in Chinese]. China Statistics Press. Stocktaking Report (2011). Child Welfare in China. Retrieved from http://uploads/soft/1_110531163254.pdf

Schaufeli, W. B., Salanova, M., González-Romá, V., \& Bakker, A. B. (2002). The measurement of engagement and burnout: A two sample confirmatory factor analytic approach. Journal of Happiness Studies: An Interdisciplinary Forum on Subjective Well-Being, 3(1), 71-92. http://dx.doi.org/10.1023/A:1015630930326

Senaratna, B. (2012). Left-behind children of migrant women: Difficulties encountered and strengths demonstrated. Sri Lanka Journal of Child Health, 41(2), 71-75. http://doi.org/10.4038/sljch.v41i2.4394

Sharma, B. R., \& Bhaumik, P. K. (2013). Student engagement and its predictors: An exploratory study in an Indian business school. Global business review, 14(1), 25-42. http://dx.doi.org/10.1177/0972150912466364 
Shen, M., Gao, J., Liang, Z., Wang, Y., Yukai, D., \& Stallones, L. (2015). Parental migration patterns and risk of depression and anxiety disorder among rural children aged 10-18 years in China: A cross-sectional study. BMJ Open.

Sinatra, G. M., Heddy, B. C., \& Lombardi, D. (2015). The challenges of defining and measuring student engagement in science. Edu. Psychologist, 50(1), 1-13. http://dx.doi.org/10.1080/00461520.2014.1002924

Skinner, E. A., Wellborn, J. G., \& Connell, J. P. (1990). What it takes to do well in school and whether I've got it: A process model of perceived control and children's engagement and achievement in school. Journal of Educational Psychology, 82(1), 22-32. http://dx.doi.org/10.1037/0022-0663.82.1.22

Skinner, E. A., Kindermann, T. A., \& Furrer, C. J. (2009). A motivational perspective on engagement and disaffection: Conceptualization and assessment of children's behavioral and emotional participation in academic activities in the classroom. Educational and Psychological Measurement, 69(3), 493-525.

Su, S., Li, X., Lin, D., Xu, X., \& Zhu, M. (2012). Psychological adjustment among left-behind children in rural China: the role of parental migration and parent-child communication. Child: Care, Health and Development, 39(2), 162-170. https://doi.org/10.1111/j.1365-2214.2012.01400.x

Tao, S., Yu, L., Gao, W., \& Xue, W. (2016). Food preferences, personality and parental rearing styles: Analysis of factors influencing health of left-behind children. Quality of Life Research, 25(11), 2921-2929. Retrieved from https://link.springer.com/article/10.1007\%2Fs11136-016-1317-3

Tan, C., Luo, J., Zong, R., \& Fu, C. (2010). Nutrition knowledge, attitudes, behaviours and the influencing factors among non-parent caregivers of rural left-behind children under 7 years old in China. Public Health Nutr, 13(10), 1663-1668. https://doi.org/10.1017/S1368980010000078

UNICEF. (2014). Children in China: An atlas of social indicators. Beijing: United Nations Children's Fund.

Upadyaya, K., \& Salmela-Aro, K. (2013). Development of school engagement in association with academic success and well-being in varying social contexts: A review of empirical research. European Psychologist, 18(2), 136-147. http://dx.doi.org/10.1027/10.

Wang, M. T., \& Eccles, J. S. (2013). School context, achievement motivation, and academic engagement: A longitudinal study of school engagement using a multidimensional perspective. Learning and Instruction, 28, 12-23. http://dx.doi.org/10.1016/j.lear

Wang, L., \& Holland, T. (2011). In search of educational equity for the migrant children of Shanghai. Comparative Education, 47(4), 471-487.

Wehlage, G. G., Rutter, R. A., Smith, G. A., Lesko. N., \& Fernandez, R. R. (1989). Reducing the risk: Schools as communities of support. The Falmer Press. https://doi.org/10.1177\%2F019263658907351311

Willms, J. D. (2003). Student engagement at school: A sense of belonging and participation; Results from PISA 2000. Retrieved from http://www.oecd.org/education/school/programmeforinternationalstudentassessment pia/33689437.pdf

Wu, X., \& Ding, J. (2004). Report survey on left-behind children in rural China. Website of Beijing Education. Retrieved from http://www.bjedu.cc/html/jiaoshiyuandi/diaoyanbaogao/2009/0602/57703.html

Xin, R. E., \& Zhang, Z. X. (1992). Investigate on 24013 city children's behavioral problems in 26 units of 22 provinces. Shanghai Arch. Psychiatry, 4, 47-55. (In Chinese)

Xu, Q. G., Guan, X., \& Yao, F. (2011). Welfare program participation among rural-to-urban migrant workers in China. International J. of Social Welfare, 20(1), 10-21. https://doi.org/10.1111/j.1468-2397.2009.00713.x

Ye, J., \& Pan, L. (2011). Differentiated childhoods: Impacts of rural labor migration on left-behind children in China. The Journal of Peasant Studies, 38(2), 355-377. https://doi.org/10.1080/03066150.2011.559012

Ye, J., Murray, J., \& Wang, Y. (2005). Left-behind children in rural China. Beijing: Social Sci. Academic Press.

Zhao, X., Jian, C., Chen, M. C., \& Lv, X. L. (2014). Left-behind children in rural China experience higher levels of anxiety and poorer living conditions. Acta Paediatrica, 103(6). https://doi.org/10.1111/apa.12602

\section{Copyrights}

Copyright for this article is retained by the author(s), with first publication rights granted to the journal.

This is an open-access article distributed under the terms and conditions of the Creative Commons Attribution license (http://creativecommons.org/licenses/by/4.0/). 